Central Washington University

ScholarWorks@CWU

All Faculty Scholarship for the College of the Sciences

7-2018

Measuring and Evaluating Safety Maturity of Construction Contractors: Multicriteria Decision-Making Approach

Ali A. Karakhan

Sathyanarayanan Rajendran

John Gambatese

Chukwuma Nnaji

Follow this and additional works at: https://digitalcommons.cwu.edu/cotsfac

Part of the Civil Engineering Commons, and the Construction Engineering and Management Commons 
To cite this paper: Karakhan, A., Rajendran, S., Gambatese, J., \& Nnaji, C. (2018). Measuring and Evaluating Safety Maturity of Construction Contractors: Multicriteria Decision-Making Approach. Journal of Construction Engineering and Management, 144(7), 04018054.

The published version of the paper is available in the ASCE Library thru this link.

\title{
Measuring and Evaluating Safety Maturity of Construction CONTRACTORS: A Multicriteria DeCision-MAKing APPROACH
}

\author{
Ali Karakhan ${ }^{1}$; Sathyanarayanan Rajendran ${ }^{2}$; John Gambatese ${ }^{3}$; and Chukwuma Nnaji ${ }^{4}$
}

\begin{abstract}
Evaluating safety maturity of construction contractors before awarding the contract is an effective strategy that many owners have started to implement. Given the importance of workplace safety, awarding the contract to safer contractors can enhance project performance outcomes in terms of safety, quality, cost, and schedule. Safety maturity is one quality of a construction organization encompassing interdependent factors that can be used to evaluate expected safety performance. However, there is no formal decision-making framework available in literature that owners can use to evaluate contractor safety maturity. The present study aims to bridge this gap in safety knowledge by proposing a decision-making framework that can be utilized to evaluate safety maturity of construction contractors. The development of the decision-making framework included two tasks. First, an integrative literature review to identify influential safety maturity factors and their potential indicators was performed. The result of the review revealed seven factors (safety leading indicators, safety lagging indicators, safety and supervisory personnel, system maturity and resiliency, pre-construction services, technology and innovation, and safety culture) that influence safety maturity of construction contractors. Second, the identified factors, and their indicators, were integrated into a formal multicriteria decision-making method, referred to as Choosing by Advantages (CBA), to evaluate the safety maturity of five construction contractors on a selected case study project. The proposed framework is expected to provide practical and theoretical directions on how to evaluate contractor safety maturity using relevant evaluation factors and sound decision-making methods.
\end{abstract}

\footnotetext{
1 PhD Student, School of Civil and Construction Engineering, Oregon State University, Corvallis, OR 97331; Email: karakhaa@oregonstate.edu

2 Associate Professor, Engineering Technologies, Safety, and Construction Department, Central Washington University, Ellensburg, WA 98926.

3 Professor, School of Civil and Construction Engineering, Oregon State University, Corvallis, OR 97331.

4 PhD Student, School of Civil and Construction Engineering, Oregon State University, Corvallis, OR 97331.
} 


\section{Introduction}

Construction safety in the United States (US) remains a source of concern to construction stakeholders. Due to the often disjointed, complex, and fragmented nature of construction operations, the construction industry has been one of the most hazardous industries in the US in terms of the number of occupational fatal and non-fatal injuries. The construction industry often incurs fatal injuries at a disproportionate rate when compared with other industries. In 2015, the construction industry experienced the highest number of occupational fatal injuries (937 fatalities) and the fourth highest fatal injury rate (10.1 fatalities per 100,000 full-time equivalent workers) among US industries (BLS, 2016). Along with human suffering, significant economic and social consequences are associated with the occurrence of construction accidents.

Many parties have significant control of and/or influence on construction worker safety and health. A number of studies identify the owner's commitment to safety as one of the most effective means to ensure a high level of safety during construction (Gambatese, 2000a; Hinze, 2006; Huang \& Hinze, 2006a; Toole, 2002). Facility owners can select construction contractors who demonstrate a record of safety excellence (Toole et al., 2016) or demand that design professionals address worker safety in the project design (Tymvios \& Gambatese, 2016). Similarly, facility owners can mandate the inclusion of safety requirements in construction contracts (Gambatese, 2000a; Halowell et al., 2013). Notably, selection of contractors based, in part, on safety is one of the major strategies that project owners can implement to improve project safety performance (Gambatese, 2000a; Hinze, 2006; Huang \& Hinze, 2006a).

\section{Point of Departure}

Given the significant role that project owners can play with respect to influencing safety, previous research has emphasized owner commitment and involvement in safety. Levitt et al. (1981), as cited in Huang and Hinze (2006a), observed that facility owners who consider safety performance indicators in the construction contractor selection criteria typically encounter fewer construction incidents on their projects than those who do not place similar emphasis on evaluating contractor safety during the process of awarding construction contracts. In a similar effort, Huang and Hinze (2006a) performed statistical analysis on data collected from 81 interviews with facility owners. The 
researchers found that placing a high emphasis on safety performance indicators when selecting a construction contractor is often associated with superior safety performance.

Despite the consensus among industry stakeholders and academics that evaluating safety performance of construction contractors is a critical step before awarding the contract, there is no decision-making model or framework available, either in theory or practice, that project owners can use to evaluate safety maturity of potential contractors. In fact, owners were typically perceived to lack the necessary in-house expertise and resources to holistically evaluate the safety maturity of potential contractors using a comprehensive approach that relies on evaluating all potential safety factors and indicators (Tymvios \& Gambatese, 2016). The development of such a model or framework that includes a systematic evaluation of all potential factors influencing safety performance of construction contractors would serve as an invaluable contribution to bridge this gap in safety knowledge.

The objective of the present study is to develop a decision-making framework that can be used to evaluate contractor safety maturity before awarding the contract. Safety maturity is defined by the authors as a quality that represents the level of experience, responsibility, interdependence, and reliability within an organization and at different levels (project, team, and individual) with respect to occupational safety and health $(\mathrm{OSH})$. It reflects the maturity of the organization, the resiliency of the production system, and the competence of the workforce. Accordingly, safety maturity should be ideally measured by the level of the overall maturity (organizational, system, and behavioral), as opposed to sole reliance on evaluating the maturity of the safety management system (Foster \& Hoult, 2013). That is, safety maturity is not equivalent to the maturity of the safety management system although they are interconnected. Development of the decision-making framework includes two tasks: (1) the identification of influential factors and indicators that influence contractor safety performance during construction (i.e., safety maturity factors and indicators), and (2) a practical demonstration of how owner representatives and practitioners in the field can integrate the identified safety maturity factors and indicators into a decision-making method to evaluate safety maturity of construction contractors. Given its properties (outlined below) which are proven to be preferable over other multiple-criteria decision analysis (MCDA) methods (Arroyo et al., 2014; Suhr, 1999), the researchers selected the Choosing by Advantages (CBA) system as a quantifiable decision-making tool to evaluate safety maturity of construction contractors. 


\section{Choosing by Advantages (CBA) Decision-Making System}

CBA is a decision-making tool and lean method used in multiple fields to make sound decisions about the selection of an optimal alternative among a list of alternatives with respect to different selection factors. Previous research indicated that employing CBA in construction-related decisions is proven to be an effective method to achieve congruent and sound decision-making (Arroyo et al., 2014, 2016). With respect to construction, CBA has been implemented in the selection of green roofs (Grante \& Jones, 2008), damping walls (Nguyen et al., 2009), rebar terminators in steel reinforcement design (Parrish \& Tommelein, 2009), superstructure and conceptual designs (Lee et al., 2010; Kpamma et al., 2015), sustainable building materials (Arroyo, 2014), pre-construction designs (Abraham et al., 2013), sustainable design choices (Arroyo et al., 2014), window types (Kpamma et al., 2016), heating, ventilation, and air-conditioning (HVAC) systems for a net zero energy facility (Arroyo et al., 2016), fall-protection safety measures (Karakhan et al., 2016), concrete type (Mollo \& Emuze, 2017), and other construction-related materials and operations.

CBA has a number of advantages over other MCDA methods that can enable decision-makers to achieve desirable outcomes. One notable advantage is that the CBA steps (described below) can help decision-makers to establish a transparent and collaborative environment during the selection process (Kpamma et al., 2015; Suhr, 1999). A positive decision-making environment during the process of evaluating potential construction contractors is crucial toward achieving sound decisions. In addition, the CBA process can facilitate and expedite the process of reaching consensus among decision-makers by deferring subjective judgements to the last responsible moment until the optimal trade-offs among important factors are entirely perceived (Arroyo et al., 2014). Basing the evaluation procedure only on the importance of positive attributes of alternatives (e.g., weighting advantages of alternatives) that can bring value to decision-makers, rather than evaluating both advantages and disadvantages of alternatives, is a critical factor behind the success of CBA. Evaluating both advantages and disadvantages of alternatives leads to double-counting (Suhr, 1999). Focusing only on value-added activities is what matters to decision-makers, and, therefore, the CBA approach is preferred over other MCDA methods when evaluating potential alternatives (Suhr, 1999). To clarify how double-counting can impact the decision-making process, one can consider that an evaluation is being performed to decide between two alternatives. Identifying that the first alternative possesses greater significant attributes than the 
second alternative with regard to a certain criterion directly implies that the second alternative possesses less significant attributes with regard to that particular criterion. However, if both the advantages and disadvantages were evaluated and assigned a level of importance, the decision-makers may encounter the issue of double-counting the importance level of the first alternative, i.e., aggregating both the advantage of the first alternative and the disadvantage of the second alternative. Finally, CBA does not assume linear trade-offs between factors as other MCDA methods may assume (Arroyo et al., 2014). Linear trade-offs are oftentimes unrealistic in real-life construction decision-making problems (Arroyo et al., 2014).

Evaluating potential alternatives using sound decision-making methods and a comprehensive list of factors and evaluation criteria reveals accurate decisions and, accordingly, leads to effective and proactive actions. Such actions can eventually influence project performance outcomes in a positive manner.

\section{Research Methodology: Integrative Literature Review to Identify Safety Maturity Factors and Indicators}

A factor is a component of a decision used to assess the quality and performance of an alternative or a list of potential alternatives (Suhr, 1999). A factor consists of multiple interdependent characteristics that can be evaluated in multiple ways to quantify the quality and performance of an alternative, or a list of alternatives, with respect to the factor of interest. One way to evaluate a factor is by identifying relevant indicators and quantifying their level of effectiveness. An indicator is defined as an observable and quantifiable characteristic that can be used to evaluate the extent to which the quality or performance with respect to a specific factor is satisfied. For instance, safety climate is an indicator of the state of safety culture within an organization (Choudhry et al., 2007; Cooper, 2000; Teo \& Feng, 2009). In turn, the state of the safety culture is an influential factor of the level of contractor safety maturity.

To achieve the specified objective of this study, potential factors and indicators that influence contractor safety maturity should be identified. Due to the availability of extensive literature about safety management, the researchers decided to rely on archival literature to

identify safety maturity factors and indicators. The type of literature review selected for this study was an integrative review - a form of research method that involves reviewing and synthesizing 
representative and relevant literature on a topic in an integrated way to generate a conceptual model or identify influential factors (Torraco, 2005) - which included the following tasks. First, a Google Scholar search using keywords (e.g., measure safety performance, evaluate safety maturity, etc.) was performed to identify relevant research papers. Relevant papers from other academic search engines such as the ASCE online library and Science Direct were also identified. The reason to extend the identification of papers beyond Google Scholar was to reduce potential selection bias resulting from reliance on one search engine. Second, specific parts of each paper (title, abstract, keywords, headings and sub-headings, figures, and tables) were screened to confirm whether the topic of the identified paper was relevant, or not, to the present study. If the paper was found to be relevant, a more detailed examination of the content was performed in an effort to identify potential factors and indicators that have been reported to influence contractor safety performance. Such an influence can be any logical association, statistical correlation, causal relationship, or other type of connection between safety conditions (or outcomes) and the methods, strategies, practices, approaches, procedures, and resources used during, before, and after the start of work operations. If this type of connection was observed, then the paper was included in the review. Otherwise, the paper was disregarded and excluded from the review. Third, the researchers thoroughly read the relevant parts of each included paper and carefully examined the content for identification of factors and indicators that have been reported to influence safety performance during construction. Given the many papers describing safety studies that are available in literature, reading in detail all and every single research paper relevant to the topic of interest is impractical. Instead, it is recommended that only relevant parts or summaries (e.g., abstract) of identified papers be reviewed (Hampton \& Parker, 2011). Fourth, at this point of the review process, the researchers decided whether to include or exclude the identified factors and indicators depending on applicability to the present study, relevance to the topic, practicality of assessment, and frequency of occurrence in literature. Accordingly, indicators, such as a company newsletter promoting safety (Vecchio-Sadus \& Griffiths, 2004), that were reported in literature with a low frequency (i.e., one or two times) were excluded from the model as factors and indicators influencing safety conditions and outcomes. Finally, similar indicators were grouped into the same factors. For example, pre-project planning, value engineering, and constructability reviews were grouped under one factor named "Pre-Construction Services". 
The abovementioned integrative review and its process led to the identification of seven interdependent factors (described below) that can be used to assess the level of safety maturity of construction contractors. Based on the Bradley curve (DuPont, 2017), interdependent safety effort is the most reliable method to achieve a "world-class safety performance" (i.e., high level of safety maturity). Accordingly, the identified interdependent safety maturity factors and their indicators are considered effective measures to assess contractor safety maturity. Table 1 summarizes the safety maturity factors and indicators as reported in the literature. The values in parenthesis in the middle column of Table 1 indicate the number of studies that reported the importance of each indicator in evaluating contractor safety maturity. The references in the right column of the table support the inclusion of the factors in evaluating contractor safety maturity either directly or through one or more of the indicators. 
Table 1: Safety Maturity Factors and Indicators

\begin{tabular}{|c|c|c|}
\hline Factor & Potential Indicators (Frequency) & Supporting Literature \\
\hline $\begin{array}{l}\text { F1: Safety } \\
\text { leading } \\
\text { indicators }\end{array}$ & $\begin{array}{l}\text { Jobsite safety audits (10), safety training } \\
\text { (9), pre-task hazard analysis (7), } \\
\text { substance abuse programs (4), safety } \\
\text { incentive programs (4), toolbox } \\
\text { meetings (4), etc. }\end{array}$ & \multirow{2}{*}{$\begin{array}{l}\text { Awolusi \& Marks (2016); Choudhry et al. (2007); Hallowell et al. } \\
\text { (2013); Hinze (2006); Hinze et al. (2013); Huang \& Hinze (2006a, } \\
\text { 2006b); Jaselskis et al. (1996); Jazayeri \& Dabi (2017); Lingard et } \\
\text { al. (2013); Manuele (2009); Molenaar et al. (2009); Namian et al. } \\
\text { (2016); Rajendran (2006); Rajendran (2012); Salas \& Hallowell } \\
\text { (2016); Hallowell et al. (2013); Shea et al. (2016); Sheehan et al. } \\
\text { (2016); SmartMarket Rep. (2016); Spear (2013); Toellner (2001); } \\
\text { Vecchio-Sadus \& Griffiths (2004); Wachter (2014) }\end{array}$} \\
\hline $\begin{array}{l}\text { F2: Safety } \\
\text { lagging } \\
\text { indicators }\end{array}$ & $\begin{array}{l}\text { Recordable injury rate }(10), \text { lost time } \\
\text { injury rate }(9) \text {, experience modification } \\
\text { rate (8), OSHA citations and fines (4), } \\
\text { etc. }\end{array}$ & \\
\hline $\begin{array}{l}\text { F3: Safety and } \\
\text { supervisory } \\
\text { personnel }\end{array}$ & $\begin{array}{l}\text { Staffing for safety (10), management } \\
\text { commitment and supervisory leadership } \\
(8), \text { qualification and education }(6) \text {, time } \\
\text { commitment (5), years of experience } \\
\text { and personal competency (5), etc. }\end{array}$ & $\begin{array}{l}\text { ASSE (2017); Choudhry et al. (2007); Esmaeili \& Hallowell } \\
\text { (2011); Fung et al. (2005); Hallowell et al. (2013); Hinze (2001); } \\
\text { Hinze (2006); Huang \& Hinze (2006a, 2006b); Jaselskis et al. } \\
\text { (1996); Lingard et al. (2013); Mohamed (2002, 2003); Sawacha et } \\
\text { al. (1999); Shapira \& Simcha (2009); Shea et al. (2016); Sheehan } \\
\text { et al. (2016); Tam et al. (2004); Teo \& Feng (2009); } \\
\text { Vecchio-Sadus \& Griffiths (2004) }\end{array}$ \\
\hline $\begin{array}{l}\text { F4: System } \\
\text { maturity and } \\
\text { resiliency }\end{array}$ & $\begin{array}{l}\text { Safety management system (7), work } \\
\text { quality or quality management system } \\
\text { (6), quality/cost control and monitoring } \\
\text { (5), reporting and documentation system } \\
\text { (4), project delivery method (3), } \\
\text { contractual arrangement (3), etc. }\end{array}$ & $\begin{array}{l}\text { Behm et al. (2014); Cadieux et al. (2006); Choudhry et al. (2007); } \\
\text { Jazayeri \& Dabi (2017); Hinze (2006); Huang \& Hinze (2000a, } \\
\text { 2006b); Loushine et al. (2006); Lin \& Mills (2001); Lingard et al. } \\
\text { (2013); Liu et al. (2017); Love \& Teo (2017); Love et al. (2016); } \\
\text { Manuele (2003); Ng et al. (2005); Rajendran (2006); Rajendran et } \\
\text { al. (2012); Salas \& Hallowell (2016); Shea et al. (2016); Tam et al. } \\
\text { (2004); Teo \& Feng (2009); Teo \& Love (2017); Wanberg et al. } \\
\text { (2013) }\end{array}$ \\
\hline $\begin{array}{l}\text { F5: } \\
\text { Pre-construction } \\
\text { services }\end{array}$ & $\begin{array}{l}\text { Pre-project planning (7), value } \\
\text { engineering and constructability design } \\
\text { reviews (6), site logistics and layout } \\
\text { plans (3), off-site fabrication (3); etc. }\end{array}$ & $\begin{array}{l}\text { Gambatese (2000a, 2000b); Gambatese et al. (2007); Hare et al. } \\
\text { (2006); Hinze (2006); Huang \& Hinze (2000a); Jarrell (2014); } \\
\text { Rajendran (2006); Russell et al. (1994a); Russell et al. (1994b); } \\
\text { Sulankivi et al. (2009); Toole \& Gambatese (2008); Wanberg et } \\
\text { al. (2013); Whitman (2014) }\end{array}$ \\
\hline \multirow[t]{2}{*}{$\begin{array}{l}\text { F6: Technology } \\
\text { and innovation }\end{array}$} & $\begin{array}{l}\text { Technology: virtual reality modelling } \\
\text { (5), building information modelling (5), } \\
\text { 3D/4D computer aided design (4), } \\
\text { mobile eye-tracking (3), etc. }\end{array}$ & $\begin{array}{l}\text { Alomari et al. (2017); Bhoir et al. (2015); Ganah \& John (2015); } \\
\text { Hasanzadeh et al. (2017); Perlman et al. (2014); Rajendran \& } \\
\text { Clarke (2011); Shen \& Marks (2015); SmartMarket Rep. (2016); } \\
\text { Sulankivi et al. (2009); Tam et al. (2004) }\end{array}$ \\
\hline & $\begin{array}{l}\text { Innovation: lean practices (4), green } \\
\text { materials (4), high-performance designs } \\
\text { (4), sustainable solutions (4), etc. }\end{array}$ & $\begin{array}{l}\text { Antillon et al. (2010); Awolusi et al. (2018); Behm \& Hock (2012); } \\
\text { Behm et al. (2017); Gambatese et al. (2016); NIOSH (2011); } \\
\text { Nahmens \& Ikuma (2011); SmartMarket Rep. (2013, 2016) }\end{array}$ \\
\hline $\begin{array}{l}\text { F7: Safety } \\
\text { Culture }\end{array}$ & $\begin{array}{l}\text { Worker involvement in } \\
\text { decision-making (9), teamwork and } \\
\text { communication (8), safety climate (8), } \\
\text { owner involvement in safety (6), } \\
\text { organizational commitment to safety } \\
(4), \text { work environment (3), etc. }\end{array}$ & $\begin{array}{l}\text { Aksorn \& Hadikusumo (2008); Chinda \& Mohamed (2008); } \\
\text { Choudhry et al. (2007); Cooper (2000); Fung et al. (2005); } \\
\text { Gambatese (2000a); Gao et al. (2016); Hallowell et al. (2013); } \\
\text { Hinze (2006); Huang \& Hinze (2000a, 2006b); Lingard et al. } \\
\text { (2013); Mohamed (2002, 2003); Molenaar et al. (2009); Sawacha } \\
\text { et al. (1999); Shea et al. (2016); SmartMarket Rep. (2016); Teo \& } \\
\text { Feng (2009); Toole (2002); Vecchio-Sadus \& Griffiths (2004); } \\
\text { Zahoor et al. (2017) }\end{array}$ \\
\hline
\end{tabular}

\section{Safety Leading Indicators}

It is widely agreed among safety professionals that leading indicators of safety are an effective means to evaluate contractor safety performance. Safety leading indicators are proactive, pre-incident measurements consisting of multiple levels of safety protections carried out before the start of (or during) the construction phase, at both the organization and project levels. One drawback 
of leading indicators is that they do not necessarily eliminate workplace hazards. That is, many safety practices that are considered leading indicators are aimed at improving worker behaviors or enhancing hazard recognition abilities so that unsafe acts are minimized, as opposed to eliminating hazardous conditions present in the workplace. However, safety leading indicators can still prevent workplace accidents and their presence is essential in order to establish an effective safety plan (Hinze et al., 2013). Previous studies repeatedly confirmed the importance of assessing safety leading indicators in predicting safety performance of construction contractors. Awolusi and Marks (2016) indicated that using behavioral sampling techniques and observing workers while they are engaged in a work operation is an effective measure of workplace safety performance. Relatedly, Namian et al. (2016) concluded, based on empirical data collected from 51 construction projects in the US, that effective training (e.g., high-engagement training) can significantly improve the hazard recognition ability of construction workers. Such recognition is considered an essential first step to mitigating workplace hazards (Perlman et al., 2014). A previous study that involved the analysis of 51 construction projects in the US and Canada demonstrated that the amount of safety training given to workers on a particular project is statistically associated with lower injury rates (Huang \& Hinze, 2006a). The same study (Huang \& Hinze, 2006a) also found that requiring field personnel to pass a drug test has a positive impact on safety performance during construction.

\section{Safety Lagging Indicators}

Unlike safety leading indicators, lagging indicators of safety are reactive measures and cannot be used to prevent incidents or predict future safety performance of construction contractors (Manuele, 2009). That is, safety lagging indicators are retrospective measures of safety performance by which the assessment is linked to the outcome of an incident after the fact (Toellner, 2001) that some level of suffering and/or economic loss have already been incurred at both individual and organizational levels. In addition, lagging indicators do not provide a reasoning of why such an incident has occurred or what the preconditions that led to the occurrence of a particular incident are and, therefore, may not accurately reflect the severity level of injuries (Toellner, 2001). Accordingly, the value of safety lagging indicators remains questionable by many OSH professionals (Manuele, 2009). However, safety lagging indicators are still effective when, for example, assessing long-term safety performance, comparing safety performance of two or more projects/contractors within the same industry division, evaluating current safety performance with regard to past performances, or 
even assessing safety performance of the entire industry. Additional benefit of the use of safety lagging indicators is that they are objective, quantifiable in nature, and easily measured indicators (Wachter, 2014). Importantly, leading and lagging indicators of safety are supplementary to each other and should both be used, in a balanced manner, to evaluate contractor safety performance (Manuele, 2009; Wachter, 2014).

\section{Safety and Supervisory Personnel}

While Occupational Safety and Health Administration (OSHA) regulations require employers to provide their employees with safe and healthy work conditions, employees have the responsibility to be vigilant of any potential safety hazards. Many construction stakeholders argue that safety is the responsibility of everyone on the jobsite (i.e., all workers are safety personnel). In this regard, certified OSH professionals and construction superintendents are the most impactful personnel when it comes to influencing worker behavior in a workplace (Hinze, 2006). Certified OSH professionals are defined as those competent individuals with the capability, education, experience, and skills to identify patent and latent hazards in a workplace (BCSP, 2017). Importantly, safety and supervisory personnel (SSP) should have the authority to stop the work whenever deemed necessary. Rajendran et al. (2012) attributed the significant reduction of fatal and non-fatal workplace injuries in construction over the past three decades, in part, to the role of OSH professionals. In a similar manner, project superintendents - those who supervise and manage day-to-day construction operations and lead the construction workforce in the workplace - can equally play an important role toward ensuring a high level of workplace safety (Perlman et al., 2014; Hinze, 2006) in addition to managing work schedule, construction cost, work quality, and workplace/labor relations. Safety accountability is often perceived as the contractor's responsibility - particularly, middle managers such as project superintendents (Hinze, 2006). Hinze (2006) observed that when an OSH professional is not fully dedicated to a project, it is standard practice to assign the responsibility of safety to superintendents who are often regarded as the second-most competent employee to oversee workplace safety efforts.

Because safety and supervisory personnel are of vital importance to ensuring safe work operations, previous research suggested that personnel qualifications of middle management (e.g., OSH professionals) be advanced and their time commitment to the safety effort be increased. Huang and Hinze (2006a) found that hiring a full-time representative to oversee the safety effort leads to 
superior safety performance. As such, Hinze (2001) called for increasing the number of staff dedicated to safety as the overall number of workers in a project increases. Based on the aforementioned discussion and review of literature (Adam et al., 2004; ASSE, 2017), the following indicators can be considered critical when evaluating the competency of frontline safety supervisors: (1) years of construction/safety experience in the field, (2) education and certification qualifications, and (3) time commitment to the project (ASSE, 2017); other potential indicators of the competency and capability of the safety staff are summarized in Table 1.

\section{System Maturity and Resiliency}

Highly competent contractors with a mature and high-standard production system are desired from multiple perspectives. Their ability to safely deliver projects on schedule, within budget, and in compliance with high-quality standards is highly regarded. A safety management system including its essential components (e.g., incident reporting and investigation) is one potential indicator of the level of system maturity and resiliency. Work quality is another potential indicator of the level of system maturity and resiliency. Typically, continuous improvement of work quality and workplace safety is a top priority for facility owners and building developers, especially in response to the increasing number of lawsuits against project owners brought about by injured workers or their families (Huang \& Hinze, 2006a). Several studies have found an apparent alignment between safety and quality management systems (Love et al., 2016; Rajendran et al., 2012; Teo and Love, 2017). Safety incidents are major deviations from the safety plan and can be considered a defect of the entire system. Manuele (2003) argued that safety and quality could be used interchangeably in many contexts. Wanberg et al. (2013) further added that safety and quality management systems are oftentimes identical in terms of structure and content. This similarity means that performing quality inspections and safety audit can be performed analogously, perhaps by OSH professionals (Rajendran et al., 2012). Rajendran et al. (2012) point out that many employers have already started to assign quality management responsibilities to safety departments and vice versa.

By adopting and implementing a formal quality management system (e.g., ISO 9001), a substantial reduction in construction defects, warranty callbacks, and amount of rework can be achieved (Love et al., 2016; Rajendran et al., 2012), influencing project cost and schedule positively. Moreover, a high quality work environment generates a culture and mindset of continuous improvement among field personnel. This positive mindset can be employed in many directions, 
including construction site safety, to improve project performance outcomes. In addition, a continuous improvement mentality provides a rewarding environment to those who have a desire for a high level of professionalism and motivates workers to behave in a positive and safe manner. Taking into account that unsafe acts of people are one of the primary reasons behind construction accidents, improving worker behaviors is a key step toward achieving safe outcomes. Previous studies found positive statistical correlation between workplace injuries and quality defects (the amount of rework) (Love et al., 2016; Teo \& Love, 2017; Wanberg et al., 2013). Based on this finding it can be argued that a construction contractor with a mature and resilient production system (e.g., effective quality and safety management system) is more likely to be successful in reducing workplace incidents.

\section{Pre-Construction Services}

Pre-construction services are practices used in the pre-construction planning stage before the start of construction to optimize the use of human resources and capital assets and to identify possible opportunities that can improve the viability and efficiency of a project. Pre-construction services entail preparing a risk management plan by performing value engineering and constructability reviews , preparing site logistics and layout plans, and conducting other critical activities aimed at maximizing customer satisfaction while minimizing potential cost overruns, schedule delays, and other potential construction risks. In particular, safety conditions are observed to be improved when effective pre-construction services are carried out throughout the planning and design phases (Whitman, 2014).

One of the most effective pre-construction services is constructability reviews conducted before the start of construction. Constructability is "a project characteristic that reflects the ease with which a project can be built and the quality of its construction documents" (Gambatese et al., 2007). According to the Constructability Committee within the Construction Institute (CI) of the ASCE, constructability is the process of integrating "construction knowledge and experience in the planning, design, procurement, construction, operation, maintenance, and decommissioning phases of projects consistent with overall project objectives." In an analysis of four case study projects, Russell et al. (1994a) observed that effective constructability reviews can facilitate the construction process and improve the quality of production while improving building aesthetics, shortening project schedule, and generating additional business value. With regard to safety, constructability efforts entail early involvement of construction experience to review construction processes from start to finish and to take advantage of potential opportunities to eliminate safety and quality 
deficiencies. In addition, constructability reviews improve design feasibility so that the facility design can be constructed safely and in a timely manner. Producing designs with a high level of constructability can reduce the amount of rework and, thus, worker exposure to safety hazards (Russell et al., 1994a, 1994b; Wanberg et al., 2013).

Another effective pre-construction service in order to maintain a safe work operation is early planning for site logistics and layout plans. Effective planning of site logistics and layout plans can maximize the use of space, allowing safe access for materials and project personnel into and out of the jobsite (Whitman, 2014). On a parallel track, developing a project work plan/schedule is critical toward achieving project goals, including worker safety. Safety data can be integrated into work schedule using software programs to adjust, say, the critical path activities and the sequence of performing these activities (Hare et al., 2006). The sequence and timing of constructing design elements can influence worker interactions with each other and possibly safety outcomes. For instance, a congested work environment can introduce substantial safety risk to construction workers (Esmaeili et al., 2015), especially in the presence of multiple working crews employed by different subcontractors. Gambatese and Alomari (2016) described the construction site as a system of elements with multiple connections between workers, activities, and design elements where each element has a potential to influence construction worker safety. An effective work schedule should include considerations for severe weather conditions, such as the use of prefabrication and modularization, to eliminate potential negative impacts of severe weather conditions on worker safety and health.

\section{Technology and Innovation}

The advancement of technology and identification of numerous innovative solutions have led to substantial progress in the construction industry, bringing about significant enhancement to construction projects in terms of safety, quality, cost, and schedule (Ozorhon \& Oral, 2016). Previous research has identified numerous technologies (e.g., automation and visualization tools) and innovative solutions (e.g., green materials and innovative designs) that can be implemented during or before construction in order to enhance project performance outcomes, including construction safety.

With regard to the design and planning stage of construction projects, building design and construction professionals have started to incorporate virtual reality technologies into their projects to mitigate potential construction hazards and promote workplace safety. Virtual reality technologies used to visualize the physical and functional characteristics of construction facilities provide design and 
construction professionals with the ability to identify potential issues in the design of the facility. Such ability is facilitated by the creation of versatile virtual reality models that can be collaboratively shared with different project teams. The rationale behind virtual reality models is that the project should be built "virtually" prior to building it "physically" so that potential obstacles are eliminated before the start of construction (Smith, 2007). The visualizing of a construction workplace can assist safety personnel in the process of identifying potential safety hazards that are not readily detectable in two-dimensional (2D) drawings (Shen \& Marks, 2015). In fact, previous experimental studies indicated that even experienced construction professionals with many years of experience may not be able to identify a high percentage of construction hazards in a workplace using 2D drawings, but this percentage can be substantially upgraded when virtual reality models are utilized (Perlman et al., 2014).

The use of technology [e.g., Building Information Modeling (BIM)] is also found to improve communication and collaboration among workers and between different teams (Alomari et al., 2017). The use of multi-directional communication (e.g., digital 4D models facilitated by mobile BIM units in the workplace) is found to be of significance usefulness during construction (Ganah \& John, 2015) because it can facilitate information exchange among project teams in a high-quality and efficient manner (Ganah \& John, 2015). Effective communication improves workplace safety. For instance, automatic clash detection using virtual simulation modelling can spontaneously inform project teams about identified clashes and the need to eliminate them, leading to substantial reduction in the amount of rework associated with construction operations. Eliminating rework can reduce worker exposure to safety hazards and lead to improved safety outcomes.

Value generation facilitated by the incorporation of lean thinking into the design and construction processes is a form of innovation that can be used to enhance workplace safety. Research has consistently confirmed the synergies between lean thinking and safety management (Antillon et al., 2010; Gambatese et al., 2016). Lean thinking is a production management-based approach aimed at maximizing value generation and minimizing non-value activities (i.e., waste) through the reduction of process variability, improvement of workflow stability, enhancement of team communication, and desire to continuously improve work conditions and process reliability. The result of a recent survey distributed to industry professionals indicates that a majority of the study participants stated that adopting lean thinking practices influence workplace safety conditions positively (Gambatese et al., 2016). As construction contractors adopt more technologies and innovative practices, the potential for 
improving workplace conditions increases, demonstrating a distinguished maturity in terms of safety and non-safety outcomes.

\section{Safety Culture}

Safety culture is a property reflecting personal (e.g., values and attitudes), behavioral (e.g., competencies and patterns of behaviors), and other features that represent the accumulated learning of a group of people in an organization and that determine organizational and individual commitment to safety (Cooper, 2000). The personal and behavioral features are desired when they are employed in such a way as to minimize exposure of members of the organization to hazardous situations. Safety culture extends beyond safety policies, practices, and procedures implemented in the workplace (SmartMarket Rep., 2016); safety culture is a subset of organizational culture that is believed to influence workplace safety conditions and outcomes (Cooper, 2000; Mohamed, 2003), productivity, work quality, work satisfaction, and work methods (Teo \& Feng, 2009), either positively or negatively. Lingard et al. (2013) proposed a multi-level measurement model combining leading and lagging indicators along with safety culture indicators in order to evaluate safety and health performance in the construction industry. Lingard et al. argued that the state of safety culture "measured at one point in time statistically predicts the occurrence of accidents or injuries in a subsequent time period." Accordingly, safety culture in the present study is considered an influential factor to determine the level of contractor safety maturity. Multiple indicators can be used to assess the state of safety culture within an organization, as shown in Table 1. Teo and Feng (2009) empirically examined the relationship between safety culture and safety climate as an indicator of the state of safety culture. The results of the study reveal that safety climate has significant influence on personal, behavioral, and other aspects of safety culture.

\section{Evaluating Safety Maturity: A Case Study}

Due to its previously stated advantages, the researchers propose the CBA system as a quantifiable decision-making tool to assess safety maturity of construction contractors. Using the seven identified factors and their indicators (shown in Table 1), a case study project on the Oregon State University (OSU) campus was selected and a CBA evaluation was performed to demonstrate the application of the proposed decision-making framework in evaluating contractor safety maturity. 
In October 2013, OSU released a request for proposals (RFP) to invite potential construction contractors interested in providing construction manager/general contractor $(\mathrm{CM} / \mathrm{GC})$ services for the case study project, a three-story building for the School of Chemical, Biological, and Environmental Engineering (CBEE) at OSU. The footprint of the facility is distributed over 5,574 square-meters $(60,000$ square-feet) with a total budget of $\$ 40$ million. The facility includes research laboratories, teaching classrooms, administrative, staff, and faculty offices, and other spaces. The structure of the building is supported by five, 16-meter (52-foot) tall, free-standing concrete shear walls, engineered to withstand potential earthquakes and wind loads. Large windows and floor-to-ceiling glass walls are incorporated into the design to maximize the use of natural lighting throughout the building's interior (OSU, 2016).

The RFP included information about the contractor selection criteria, the project specifications, requirements, and scope of work. Submitted proposals were required to conform to the requirements mentioned in the RFP, including the submission of specific documentation to address thirteen evaluation criteria established by the owner. The thirteen evaluation criteria were: firm background (10 points), qualification of key personnel (25 points), firm's experience in the Pacific Northwest (10 points), construction manager/general contractor (CM/GC) role (20 points), cost control (10 points), project management techniques (10 points), workforce diversity plan (15 points), proposed work/plan schedule (10 points), proposed site coordination/logistics (10 points), sustainability (5 points), safety (10 points), CM/GC fee (10 points), and pre-construction services (5 points). Nine construction firms active in the Pacific Northwest region of the US responded to the RFP by submitting a proposal outlining their capability and competency to build the project and providing a detailed plan on how they plan to approach the project. A contractor selection committee consisting of four representatives of OSU departments evaluated the nine RFP submittals based on the selection criteria and their level of importance stated above.

\section{CBA Application to Evaluate Contractor Safety Maturity}

A step-by-step CBA evaluation of the safety maturity of construction contractors is described below.

\section{Step \#1: Consider Potential Alternatives}

Initially, nine responses to the RFP were received by the owner. The selection committee representing the owner performed an evaluation analysis, referred to as weighting, rating, and calculating (WRC), 
using the thirteen evaluation criteria mentioned above and created a shortlist of five of the firms which were then invited to attend an interview with the selection committee. For the purpose of this study, the five shortlisted proposals were considered the potential alternatives for this case study.

\section{Step \#2: Identify Applicable Factors and Criteria}

An integrative literature review (previously described) led to the identification of seven safety maturity factors. These safety maturity factors and their indicators (shown in Table 1) were initially considered the evaluation factors for this case study example, but only applicable factors and indicators were used in the CBA application. That is, some factors and indicators such as safety culture indicators were excluded from the evaluation process given that the evaluation in this case is aimed at assessing contractor safety maturity before awarding the contract during which sparse information about safety culture is available. Similarly, other indicators, such as project delivery method and contractual arrangement, were also excluded from the evaluation process because they are predetermined in advance by the project owner and cannot be changed regardless to whom the contract is awarded.

The evaluation criteria (decision rules or guidelines used to assess the level of effectiveness of potential indicators) were also identified in this step of the CBA process. Evaluation criteria within CBA are typically classified to either "want" or "must" criteria (Suhr, 1999). This classification is consistent with the viewpoint of the project owner in which criteria are regarded as either "preferred" or "needed" (OSU, 2016). For example, the criterion for the safety leading indicators (F1) is considered a want criterion, i.e., greater implementation of safety administrative controls is desired. This classification means that there is no specific threshold by which alternatives would be eliminated from the decision-making process with regard to this factor. By contrast, the researchers set thresholds for some of the safety lagging indicators (F2). Specifically, industry averages for both recordable injury rate (RIR) and experience modification rating (EMR) are used as the minimum criteria for this factor. Accordingly, any alternatives not satisfying these minimum thresholds should be eliminated from the decision-making process and considered as unqualified alternatives. The complete list of factors and their corresponding criteria are shown in the left column of Table 2. Criteria $\mathrm{C}_{\mathrm{w}} 1$, for example, represents the number of safety leading indicators utilized by the contractor and is used to evaluate the safety leading indicators factor (F1). As indicated in the table, $\mathrm{C}_{\mathrm{w}} 1$ is a want criterion (the implementation of more safety leading indicators is desired). 


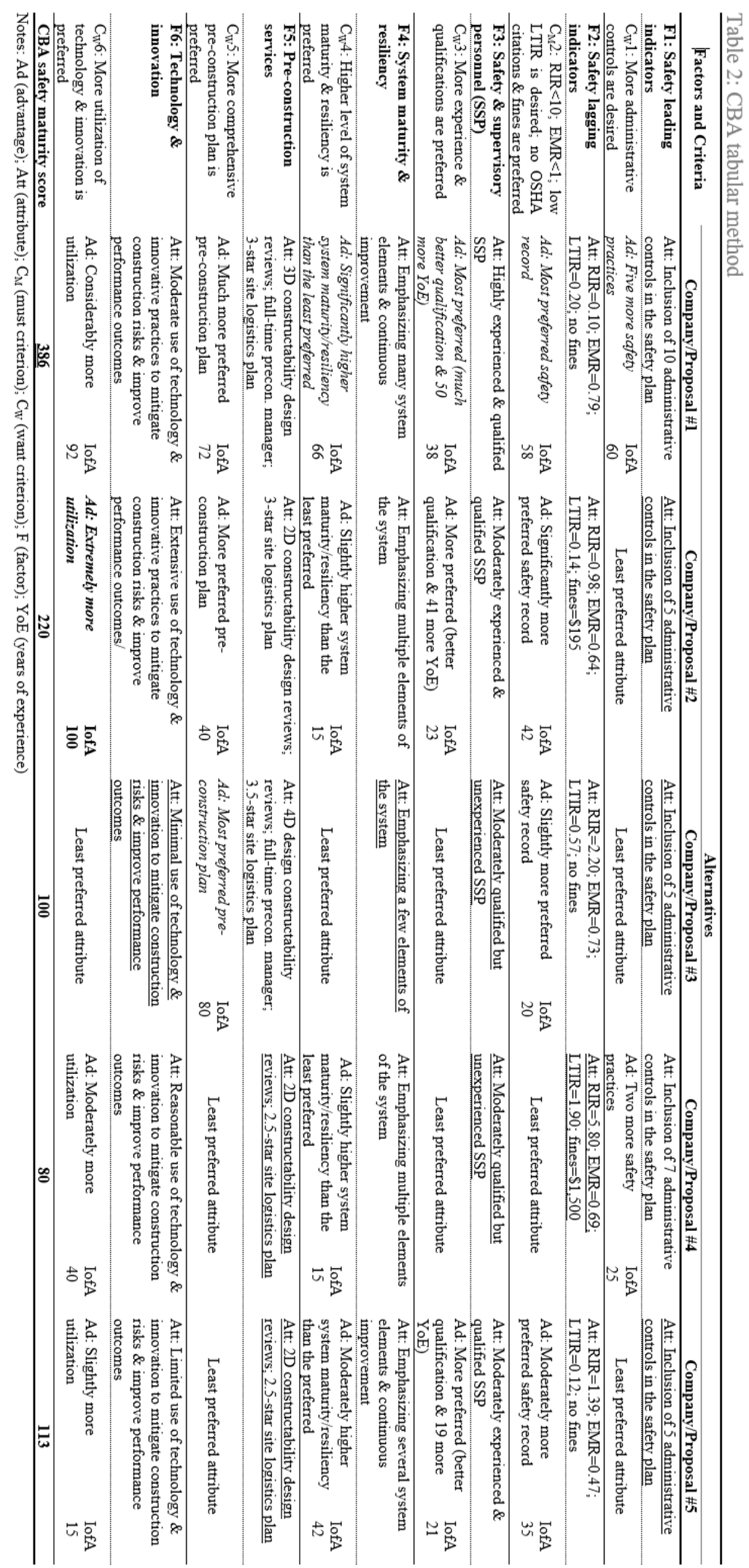




\section{Step \#3: Summarize Attributes of each Alternative}

The researchers obtained copies of the proposals from the owner for evaluation. The proposals contained detailed information about the capability and competency of the interested CM/GC firms and how each firm envisions the project and plans to proceed during the pre-construction, construction, and post-construction phases. The research team performed a systematic analysis of the five proposals in an effort to summarize potential attributes of each alternative and with respect to the applicable safety maturity factors. Table 2 summarizes the attributes of each alternative, as reported in the proposals.

\section{Step \#4: Determine Advantages of each Alternative}

After summarizing the attributes of the alternatives, the advantages of each alternative were determined using the evaluation criteria discussed in Step \#2. To determine the most advantageous attributes with respect to each factor, three tasks were performed as follows: (1) determine the least preferred attribute (shown in underlined font in Table 2) within each factor relying on the evaluation criteria; (2) determine the advantages of the remaining alternatives by measuring the difference of each attribute from the least preferred attribute; and finally (3) determine the most preferred attribute within each factor (shown in italics in Table 2).

\section{Step \#5: Decide on the Importance of Advantages (IofAs)}

An advantage is a benefit gained from the more preferred alternative over the less preferred alternative corresponding to a particular factor (Suhr 2000). Quantification of the advantages is a vital task in the CBA process. Decision-makers should collaboratively decide on the importance of advantages (IofAs) so that the total importance (i.e., value-added) of each alternative is determined. The determination of the total importance of each alternative allows decision-makers to finalize the decision-making process by selecting the most value-generating alternative. For the purpose of this study, the researchers initially attempted to meet with the original decision-makers (the owner's selection committee members) to perform this step of the CBA process. However, due to restrictions outside the control of the research team (e.g., some members of the selection committee no longer worked for the owner at the time of the study), a meeting with the selection committee was not possible. Instead, the research team - based on their experience and education, and relying on the evaluation sheet produced by the selection committee - decided on the IofAs. The evaluation sheet 
produced by the selection committee representing the owner of the project was obtained from OSU and used as a reference throughout the process of the CBA evaluation, especially with respect to deciding on the IofAs. The fact that the research team members performed the CBA evaluation by themselves may limit generalizing the results of the evaluation beyond the selected case study. However, the primary objective of the selection of the case study was to demonstrate how to perform a step-by-step CBA evaluation of contractor safety maturity using the identified safety maturity factors and indicators, as opposed to extrapolating the results of the study to other similar projects. Moreover, the evaluation was anchored to relevant facts (the attributes obtained from the RFP submittals) and objective judgements (the weighting produced by the owner's selection committee members). Basing evaluation on relevant facts and objective judgements minimizes potential bias and oftentimes reveals valid results (Suhr, 1999).

A major task in this step of the CBA process is to decide on the paramount advantage. The paramount advantage is the most value-adding advantage and is often assigned a value of 100 (Suhr, 1999). The researchers selected the additional value that the use of technology and innovation of Company \#2 generates over other advantages as the paramount advantage and, therefore, assigned to it a value of 100. This value represents the importance of this particular advantage over other advantages. Company \#2 included in its proposal an effective plan to incorporate BIM throughout the planning and construction phases of the project in order to mitigate construction risks, such as improving design feasibility and detecting potential design errors. In addition, Company \#2 included in its proposal multiple procedures (e.g., digital drawings facilitated by on-site electronic devices) that were planned to be performed during construction in order to improve buildability and worker safety.

After this determination, the paramount advantage should be used as a point of reference to decide on the importance of the other advantages. Each remaining advantage should be compared with the paramount advantage, directly or indirectly, to decide on its level of importance to the decision-makers. The researchers selected the value that the use of technology and innovation of Company \#1 generates over the least preferred attribute with respect to this factor (F6) as the second most important advantage and, accordingly, assigned an IofA of 92 to it. Company \#1 proposed the use of virtual design and construction tools throughout the project to identify construction risks, especially in terms of safety. For example, a BIM manager was to be dedicated to the project during construction to help facilitate and communicate work plans and safety procedures to field personnel. 
The value-added that the pre-construction services plans of Companies \#3 and \#1 generates were given a high level of importance (IofA $=80$ and IofA $=72$, respectively) as the plans involved multiple effective procedures to improve performance outcomes, including performing lifecycle design constructability reviews as well as preparing effective site logistics and layout plans. Any planning efforts, especially if related to safety, performed before the start of construction have greater influence than efforts carried out during construction in terms of minimizing construction safety risks and reducing the likelihood of injuries (Szymberski, 1997). Companies \#3 and \#1 explicitly expressed in their proposals that they intend to perform design-safety constructability reviews using visualization and technology tools, such as 4D modelling, to improve the quality of production in terms of safety and buildability. In its RFP submittal, Company \#1 stated "[Our team] will work closely with [the designer] to make sure construction [operations] can be performed safely, based on the design documents. Our constructability reviews often uncover ways to increase safety that aren't shown on the drawings." Moreover, both firms expressed the intent to allocate a full-time pre-construction manager to the project to facilitate the pre-construction effort. Evaluation of the site logistics and layout plans were obtained from the owner's assessment. These logistic elements can play a critical role in protecting the public and field personnel during construction, especially given that the project is located in a densely populated area on the university campus throughout the academic year.

The added value that the level of system maturity and resiliency of Company \#1 offers was then assigned the next level of importance (IofA = 66). Company \#1 indicated in its RFP submittal that the project team plans to build mock-up models, whenever possible, to detect design deficiencies and eliminate potential risks prior to on-site assembly of building components. Building mock-up models provides substantial opportunities to improve functionality, constructability, feasibility, and durability of the project design prior to assembly, minimizing potential change orders and rework during construction.

Using the same methodology, the research team assigned IofAs to the remainder of the advantages, as shown in Table 2. By summing up the IofAs of each alternative, the safety maturity score of each contractor is determined. The results indicate that Company \#1 received the highest safety maturity score with a total IofAs of 386. The remaining alternatives received significantly lower IofAs, indicating lower levels of safety maturity. Such results are not final, however, because cost implications have yet to be implemented in the evaluation process. According to the CBA process, money differences are "abstractions," not factors or advantages, and, therefore, should not 
be mixed with factors and advantages when evaluating potential alternatives. Instead, a stand-alone money-based evaluation should be performed, as outlined in the next section.

\section{Step \#6: Perform CBA Value-Cost Analysis}

CBA value-cost analysis should be typically performed as the last step of the CBA process before selecting the most preferred alternative. When the costs of the alternatives are equal, the alternative with the greatest total IofAs should be selected. Otherwise, the CBA concepts for money decision-making need to be applied. Table 3 summarizes the safety maturity score and expected total cost of each company. In this case, Company \#1 has both the greatest safety maturity score (IofAs = 386 ) and the least approximate cost (total $\mathrm{CM} / \mathrm{GC}$ fee $=\$ 820,000$ ), making it the most preferred alternative in this particular example.

Table 3: Value-cost assessment analysis

\begin{tabular}{lccccc}
\hline & \multicolumn{3}{c}{ Alternatives } \\
\cline { 2 - 5 } & $\begin{array}{c}\text { Company/ } \\
\text { Proposal \#1 }\end{array}$ & $\begin{array}{c}\text { Company/ } \\
\text { Proposal \#2 }\end{array}$ & $\begin{array}{c}\text { Company/ } \\
\text { Proposal \#3 }\end{array}$ & $\begin{array}{c}\text { Company/ } \\
\text { Proposal \#4 }\end{array}$ & $\begin{array}{c}\text { Company/ } \\
\text { Proposal } \\
\# \mathbf{n}\end{array}$ \\
\hline $\begin{array}{l}\text { Contractor safety maturity } \\
\text { (CBA evaluation) }\end{array}$ & $\mathbf{3 8 6}$ & 220 & 100 & 80 & 113 \\
\hline $\begin{array}{l}\text { Contractor overall maturity } \\
\text { (OSU evaluation) }\end{array}$ & 2,310 & 2,030 & 2,145 & 1,913 & 1,888 \\
\hline $\begin{array}{l}\text { CM/GC fee } \% \text { of estimated } \\
\text { cost of the project) }\end{array}$ & $1.95 \%$ & $3.50 \%$ & $2.45 \%$ & $2.88 \%$ & $2.50 \%$ \\
\hline $\begin{array}{l}\text { Pre-construction cost of } \\
\text { CM/GC services* }\end{array}$ & $\$ 40,000$ & $\$ 51,000$ & $\$ 37,500$ & $\$ 74,880$ & $\$ 25,000$ \\
\hline $\begin{array}{l}\text { Approximate total CM/GC fee } \\
\quad * \text { Note: The cost of the project is assumed to be } \$ 40 \text { million-the budget OSU dedicated for the project }\end{array}$ & $\mathbf{\$ 8 2 0 , 0 0 0}$ & $\$ 1,451,000$ & $\$ 1,017,500$ & $\$ 1,226,880$ & $1,025,000$ \\
\hline
\end{tabular}

\section{Discussion of CBA Evaluation Results}

Based on the CBA evaluation, Company \#1 is the most preferred alternative that both possesses the greatest safety maturity score and is the most cost-effective alternative. Rationally, this finding is expected; that is, proactive contractors who have a high level of safety maturity are expected to be more competitive and typically encounter less negative outcomes (e.g., rework and schedule delays) during construction than those who have lower levels of safety maturity. Based on an independent study, Ikpe et al. (2012) concluded that the benefits associated with proactive safety programs are three times greater than their initial costs in terms of safety and non-safety values. Construction accidents are often associated with substantial negative impacts on project outcomes and can consume as much as $15 \%$ of the total cost of construction projects (Everett \& Frank, 1996). Accordingly, elimination of 
hazards from the jobsite and reduction of accidents generate numerous benefits to stakeholders, especially construction contractors. By demonstrating a high level of safety maturity, Company \#1 was able to offer the least total GM/GC fee, improving its ability to compete against other companies. Although proactive construction contractors may initially invest more human and capital resources on their projects, these expenses are usually offset by later benefits. This return on investment is perhaps one reason why the alternative with the greatest CBA safety maturity score (Company \#1) is also the most affordable alternative in this particular case study example.

Remarkably, it is observed that the alternative with the paramount advantage (Company \#2) is not the most preferred alternative in this particular case study. This finding is derived from the fact that CBA evaluation bases decisions on the aggregated IofAs of alternatives, rather than basing decisions only on the importance of attributes of alternatives which is proven to be unsound strategy (Arroyo et al, 2014; Suhr, 1999). Another interesting finding is that the best alternative in terms of the overall maturity, i.e., capability and competency, based on the owner's evaluation also possesses the highest level of safety maturity (based on CBA evaluation), as shown in Table 3. This connection demonstrates a potential positive correlation between contractor overall maturity and safety maturity, confirming the interdependence among the identified safety maturity factors.

\section{Research Limitations}

The present study has its limitations in several respects. First, the identification of safety maturity factors and their indicators was, in part, based on the frequency of occurrence in research studies reported in literature. This frequency, while indicating awareness and potential connection of factors to safety maturity, does not necessarily reveal the level of importance or significance of the factors and their indicators in influencing contractor safety maturity. Second, the result of the CBA evaluation is only limited to the selected case study example and cannot be generalized beyond this case study. That is, it cannot be guaranteed that in other examples the alternative with the greatest safety maturity will also be the most cost-effective option. Third, CBA principles and techniques need to be learned and effectively used in order to achieve effective decisions. This learning curve may require extensive time and investment of various resources before effective decisions are merged. This is one reason why CBA implementation can be challenging during the inception phase of a project. Fourth, CBA is not applicable to every situation especially if there is a lack of data, or a single alternative. It should be mentioned, however, that the last two limitations are inherent limitations to the 
implementation of CBA in the decision-making process and not necessarily limitations of this research study. While limitations as stated above relate to the research methods and CBA process, the researchers believe that the limitations do not significantly impact the results. The rigor associated with the integrative literature review, as well as the academic process employed in the many studies from which the factors and indicators were derived, increase confidence in the importance of the identified safety maturity factors and indicators.

\section{Conclusions}

The number of occupational fatal and non-fatal injuries within the construction industry remains alarming. Keeping unsafe constructors off the jobsite can be an effective strategy to reduce the occurrence of construction accidents. In order to award construction contracts to safe contractors, a comprehensive evaluation of contractor safety maturity should be performed. However, a review of literature indicates that previous studies did not identify potential factors and indicators influencing safety maturity of construction contractors. The objective of this study is to propose a decision-making framework that can be used to evaluate safety maturity of construction contractors. First, an integrative review of literature was conducted to identify influential safety maturity factors and indicators. The result of the review revealed seven factors along with their indicators (shown in Table 1) that are likely to influence safety performance during construction. Then, a step-by-step demonstration to illustrate how to use a formal decision-making method to evaluate contractor safety maturity was performed using a selected case study project. The proposed framework utilizes the use of multiple factors and indicators reported to influence contractor safety performance. Historically, safety performance has been evaluated using a limited approach that solely considers leading and lagging indicators. Behm et al. (2014) criticized the construction industry's reliance on this approach and argued that this approach may not accurately reflect the safety maturity of construction contractors. The proposed framework addresses this issue and includes consideration of multiple interdependent factors to assess safety maturity of construction contractors. That being said, future research should further validate that the identified safety maturity factors and their indicators are accurate measures to evaluate contractor safety maturity. Such validation can include the utilization of an expert panel consisting of academics and industry professionals specialized in safety management and workforce development. 


\section{Acknowledgement}

The researchers thank the office of Capital Planning and Development within Oregon State University (OSU) facilities for its assistance with this research study. Any opinions, findings, and conclusions expressed in this study are those of the researchers and do not necessarily reflect the views of the OSU Capital Planning and Development office.

\section{References}

Abraham, K., Lepech, M., and Haymaker, J. (2013). "Selection and Application of Choosing by Advantages on a Corporate Campus Project." 21th Ann. Conf. of the Int. Group for Lean Construction (IGLC), Fortaleza, Brazil, 349-358.

Adams, P., Brauer, R., Karas, B., Bresnahan, T., and Murphy, H. (2004). "Professional certification.” Prof. Saf., 49(12), 26-31.

Aksorn, T., and Hadikusumo, B. (2008). "Critical success factors influencing safety program performance in Thai construction projects.” Saf. Sci., 46(4), 709-727.

Alomari, K., Gambatese, J., and Anderson, J. (2017). "Opportunities for using building information modeling to improve worker safety performance. Safety MDPI, http://dx.doi.org/10.3390/safety3010007.

Antillon, E., Alarcón, L., Matthew, H., and Molenaar, K. (2010). "A research synthesis on the interface between lean construction and safety management." $19^{\text {th }}$ Ann. Conf. of the Int. Group for Lean Construction. Lima, Peru.

Arroyo, P. (2014). "Exploring decision-making methods for sustainable design in commercial buildings." Doctoral dissertation, University of California, Berkeley, CA.

Arroyo, P., Tommelein, I. D., Ballard, G., and Rumsey, P. (2016). "Choosing by advantages: A case study for selecting an HVAC system for a net zero energy museum.” Energy and Buildings, 111, 26-36.

Arroyo, P., Tommelein, I., and Ballard, G. (2014). "Comparing AHP and CBA as decision methods to resolve the choosing problem in detailed design." J. Constr. Eng. Manage., 10.1061/(ASCE)CO.1943-7862.0000915, 04014063.

ASSE (American Society of Safety Engineers). (2017). "The employer's guide to hiring a safety professional." Retrieved from

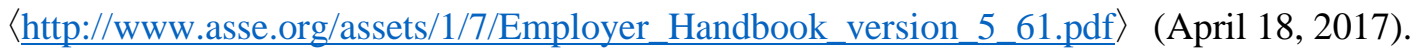

Awolusi, I. and Marks, E. (2016). "Safety activity analysis framework to evaluate safety performance in construction.” J. Constr. Eng. Manage. 10.1061/(ASCE)CO.1943-7862.0001265.

Awolusi, I., Marks, E., and Hallowell, M. (2018). "Wearable technology for personalized construction safety monitoring and trending: Review of applicable devices." Automation in Construction, 85, 96-106.

BCSP (Board of Certified Safety Professionals). (2017). "Certifications." 〈http://www.bcsp.org/Certifications〉 on (April 18, 2017).

Behm, M., and Hock, P. (2012). "Safe design of skyrise greenery in Singapore." Smart Sustainable Built Environ., 1(2), 186-205. 
Behm, M., Culvenor, J., and Genn, K. (2017). "Safe Design: A Source for Innovation in the Built Environment." Pract. Period. Struct. Des. Constr., 22(4), 04017024.

Behm, M., Lingard, H., and Bruening, J. (2014). "Validity and reliability of dependent variables: Considerations for construction safety researchers.” In CIB W099 International Conference on Achieving Sustainable Construction Health and Safety, Lund, Sweden, 577-585.

Bhoir, S., Hasanzadeh, S., Esmaeili, B., Dodd, M., and Fardhosseini, M. (2015). "Measuring construction workers attention using eye-tracking technology." 5th International/11th Construction Specialty Conference 2015, Vancouver, British Columbia.

BLS (Bureau of Labor Statistics). (2016). "National census of fatal occupational injuries in 2015." US Department of Labor. 〈https://www.bls.gov/news.release/pdf/cfoi.pdf〉 (January 13, 2017).

Cadieux, J., Roy, M., and Desmarais, L. (2006). "A preliminary validation of a new measure of occupational health and safety.” J. Safety Res., 37(4), 413-419.

Chinda, T., and Mohamed, S. (2008). "Structural equation model of construction safety culture." Eng. Construct. Architect. Manag., 15(2), 114-131.

Choudhry, R., Fang, D., and Mohamed, S. (2007). "Developing a model of construction safety culture.” J. Constr. Eng. Manage., 23(4), 207-212.

Cooper, M. D. (2000). “Towards a model of safety culture.” Saf. Sci., 36(2), 111-136.

DuPont (2017). “The DuPont Bradley Curve."

http://www.dupont.com.au/products-and-services/consulting-services-process-technologies/brands/s ustainable-solutions/sub-brands/operational-risk-management/uses-and-applications/bradley-curve.ht ml> (August 31, 2017).

Esmaeili, B., and Hallowell, M. (2011). "Diffusion of safety innovations in the construction industry." J. Constr. Eng. Manage., 138(8), 955-963.

Esmaeili, B., Hallowell, M., and Rajagopalan, B. (2015). “Attribute-based safety risk assessment. I: Analysis at the fundamental level." J. Constr. Eng. Manage., 10.1061/(ASCE)CO.1943-7862.0000980, 04015021.

Everett, J. G., and Frank Jr, P. B. (1996). "Costs of accidents and injuries to the construction industry." J. Constr. Eng. Manage., 122(2), 158-164.

Foster, P., and Hoult, S. (2013). "The safety journey: Using a safety maturity model for safety planning and assurance in the UK coal mining industry." Minerals, 3(1), 59-72.

Fung, I., Tam, C., Tung, K., and Man, A. (2005). "Safety cultural divergences among management, supervisory and worker groups in Hong Kong construction industry.” Int. J. Proj. Manag., 23(7), 504-512.

Gambatese, J. (2000a). "Owner involvement in construction site safety." Construction Congress VI: Building Together for a Better Tomorrow in an Increasingly Complex World, 661-670.

Gambatese, J. (2000b). "Safety constructability: Designer involvement in construction site safety." In Construction Congress VI: Building Together for a Better Tomorrow in an Increasingly Complex World, 650-660.

Gambatese, J., and Alomari, K. (2016). "Degrees of connectivity: Systems model for upstream risk assessment and mitigation." Accident Anal. Prev., 93, 251-259. 
Gambatese, J., Pestana, C., and Lee, H. (2016). "Alignment between lean principles and practices and worker safety behavior.” J. Constr. Eng. Manage., 10.1061/(ASCE)CO.1943-7862.0001209, 04016083.

Gambatese, J.A., Pocock, J.B., and Dunston, P.S. (Editors). (2007). "Constructability concepts and practice." Construction Institute, ASCE, Reston, VA, 1-5.

Ganah, A., and John, G. (2015). "Integrating building information modeling and health and safety for onsite construction.” Safety and Health at Work, dx.doi.org/10.1016/j.shaw.2014.10.002.

Gao, R., Chan, A., Utama, W., and Zahoor, H. (2016). "Multilevel safety climate and safety performance in the construction industry: development and validation of a top-down mechanism.” Int. J. Environ. Res. Publ. Health, 13(11), 1100-1014.

Grant, E. and Jones, J. (2008). “A Decision-making Framework for Vegetated Roofing System Selection.” Journal of Green Building, 3 (4): 138-153.

Hallowell, M. R., Hinze, J. W., Baud, K. C., and Wehle, A. (2013). "Proactive construction safety control: Measuring, monitoring, and responding to safety leading indicators." J. Constr. Eng. Manage., 139(10), 04013010.

Hampton, S., and Parker, J. (2011). "Collaboration and productivity in scientific synthesis." BioScience, 61(11), 900-910.

Hare, B., Cameron, L., and Duff, A. R. (2006) "Exploring the integration of health and safety with preconstruction planning”, Eng., Constr., Archit. Manage., 13(5), 438-450.

Hasanzadeh, S., Esmaeili, B., and Dodd, M. D. (2017). "Measuring the impacts of safety knowledge on construction workers' attentional allocation and hazard detection using remote eye-tracking technology." J. Manage. Eng., 33(5), 04017024.

Hinze, J. (2001). "Safety plus: Making zero accidents a reality." Research Summary 160-1, Construction Industry Institute, Univ. of Texas at Austin, Austin, TX.

Hinze, J. (2006). "Construction Safety." $2^{\text {nd }}$ Edition, Pearson Education, Inc.

Hinze, J., Thurman, S., and Wehle, A. (2013). "Leading indicators of construction safety performance." Saf. Sci., 51(1), 23-28.

Huang, X. and Hinze, J. (2006a). "Owner's role in construction safety." J. Constr. Eng. Manage., 10.1061/(ASCE)0733-9364(2006)132:2(164), 164-173.

Huang, X., and Hinze, J. (2006b). Owner's role in construction safety: Guidance model. Journal of Construction Engineering and Management, 132(2), 174-181.

Ikpe, E., Hammon, F., and Oloke, D. (2012). "Cost-benefit analysis for accident prevention in construction projects.” J. Constr. Eng. Manage., 138(8), 991-998.

Jarrell, W. (2014). “Construction site utilization planning best practices.” Master thesis, Auburn University, Auburn, AL.

Jaselskis, E. J., Anderson, S. D., and Russell, J. S. (1996). "Strategies for achieving excellence in construction safety performance.” J. Constr. Eng. Manage., 122(1), 61-70.

Jazayeri, E., and Dadi, G. B. (2017). "Construction safety management systems and methods of safety performance measurement: A review." Journal of safety engineering, 6(2), 15-28.

Karakhan, A., Gambatese, J., and S. Rajendran. (2016). "Application of Choosing by Advantages Decision-Making System to Select Fall-Protection Measures." 24th Ann. Conf. of the Int. Group for Lean Construction (IGLC), Boston, MA, 33-42. 
Kpamma, Z., Adinyira, E., Ayarkwa, J., and Adjei-Kumi, T. (2015). "Application of the CBA decision system to manage user preferences in the design process." J. Prof. Issues Eng. Educ. Pract., 10.1061/(ASCE)EI.1943-5541.0000258, 05015004.

Kpamma, Z., Adjei-Kumi, T., Ayarkwa, J., and Adinyira, E. (2016). "An exploration of the choosing by advantages decision system as a user engagement tool in participatory design." Architectural Engineering and Design Management, 12(1), 51-66.

Lee, H., Tommelein, I., and Ballard, G. (2010). "Lean Design Management in an Infrastructure Design-Build Project: A Case Study." 18th Ann. Conf. of the Int. Group for Lean Construction (IGLC), Haifa, Israel, 113-122.

Levitt, R., Samelson, N., and Mummy, G. (1981). "Improving construction safety performance: The user's role.” Department of Civil Engineering Technical Rep. No. 260, Stanford Univ., Stanford, Calif. (revised 1985).

Lin, J., and Mills, A. (2001). "Measuring the occupational health and safety performance of construction companies in Australia." Facilities, 19(3/4), 131-139.

Lingard, H., Wakefield, R., and Blismas, N. (2013). "If you cannot measure it, you cannot improve it: Measuring health and safety performance in the construction industry." In the 19th Triennial CIB World Building Congress, Queensland University of Technology, Brisbane, Queensland, Australia.

Liu, H., Jazayeri, E., and Dadi, G. (2017). "Establishing the influence of owner practices on construction safety in an operational excellence model. J. Constr. Eng. Manage., 143(6), 04017005.

Loushine, T., Hoonakker, P., Carayon, P., and Smith, M. (2006). "Quality and safety management in construction. "Total Qual. Manag. Bus. Excellence, 17(9), 1171-1212.

Love, P., and Teo, P. (2017). "Statistical analysis of injury and nonconformance frequencies in construction: Negative binomial regression model.” J. Constr. Eng. Manage., 143(8), 05017011.

Love, P., Teo, P., Morrison, J., and Grove, M. (2016). "Quality and safety in construction: Creating a no-harm environment.” J. Constr. Eng. Manage., 142(8), 05016006.

Love, P., Teo, P., Morrison, J., and Grove, M. (2016). "Quality and safety in construction: Creating a no-harm environment." J. Constr. Eng. Manage., 10.1061/(ASCE)CO.1943-7862.0001133, 05016006.

Manuele, F. (2003). "On the practice of safety." $3^{\text {rd }}$ Edition, John Wiley and Sons, Inc., New Jersey, USA.

Manuele, F. A. (2009). "Leading \& lagging indicators.” Prof. Saf., 54(12), 28-33.

Mohamed, S. (2002). "Safety climate in construction site environments.” J. Constr. Eng. Manage., 128(5), 375-384.

Mohamed, S. (2003). "Scorecard approach to benchmarking organizational safety culture in construction." J. Constr. Eng. Manage., 129(1), 80-88.

Molenaar, K., Park, J., and Washington, S. (2009). "Framework for measuring corporate safety culture and its impact on construction safety performance.” J. Constr. Eng. Manage., 135(6), 488-496.

Mollo, L. G., and Emuze, F. (2017). "Choosing by advantages to select concrete tasks: A project team's perception." West Africa Built Environment Research (WABER) Conference, At Accra, Ghana, 1-15.

Nahmens, I., and Ikuma, L. (2011). "Effects of lean construction on sustainability of modular homebuilding.” J. Architect. Eng., 18(2), 155-163. 
Namian, M., Albert, A., Zuluaga, C. M., and Jaselskis, E. J. (2016). "Improving hazard-recognition performance and safety training outcomes: Integrating strategies for training transfer." J. Constr. Eng. Manage., 142(10), 04016048.

$\mathrm{Ng}$, S., Cheng, K. and Skitmore, R. (2005). "A framework for evaluating the safety performance of construction contractors." Building and Environment, 40(10), 1347-1355.

Nguyen, H., Lostuvali, B., and Tommelein, I. (2009). "Decision Analysis Using Virtual First-Run Study of a Viscous Damping Wall System.” 17th Ann. Conf. of the Int. Group for Lean Construction (IGLC), Taipei, Taiwan, 371-382.

NIOSH (National Institute for Occupational Safety and Health). (2011). "Integrating occupational safety and health into the U.S. green building council LEED new construction credits: A preliminary report." Washington, D.C.

OSU (Oregon State University), (2016). "Grand opening of Johnson Hall planned at OSU.” News and Research Communications.

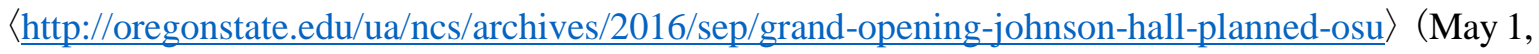
2017).

OSU (Oregon State University), (2017). "Request for proposal (RFP).” Finance and Administration-Business Affairs: Procurement and Contract Services.

$\langle$ http://pacs.oregonstate.edu/pacs/procurement/how-do-i-start/request-proposal-rfp $\rangle$ (January 18, 2017).

Ozorhon, B. and Oral, K. (2016). "Drivers of innovation in construction projects.” J. Constr. Eng. Manage., 10.1061/(ASCE)CO.1943-7862.0001234, 04016118.

Parrish, K., and Tommelein, I. (2009). "Making Design Decisions Using Choosing by Advantages." 17th Ann. Conf. of the Int. Group for Lean Construction (IGLC), Taipei, Taiwan, 501-510.

Perlman, A., Sacks, R., and Barak, R. (2014). "Hazard recognition and risk perception in construction." Saf. Sci., 64, 22-31.

Rajendran, S. (2006). "Sustainable construction safety and health rating system." Doctoral dissertation, Oregon State University, Corvallis, OR.

Rajendran, S. (2012). "Enhancing construction worker safety performance using leading indicators." Pract. Period. Struct. Des. Constr., 18(1), 45-51.

Rajendran, S., and Clarke, B. (2011). "Building information modeling: Safety benefits \& opportunities." Prof. Saf., 56(10), 44-51.

Rajendran, S., Clarke, B., and Andrews, R. (2012). "Quality management in construction: An expanding role for SH\&E professionals.” Prof. Saf., 57(11), 37-42.

Russell, J., Gugel, J., and Radtke, M. (1994a). "Comparative analysis of three constructability approaches." J. Constr. Eng. Manage., 10.1061/(ASCE)0733-9364(1994)120:1(180), 180-195.

Russell, J., Swiggum, K., Shapiro, J., and Alaydrus, A. (1994b). "Constructability related to TQM, value engineering, and cost/benefits.” J. Perform. Constr. Fac., 8(1), 31-45.

Salas, R., and Hallowell, M. (2016). "Predictive validity of safety leading indicators: Empirical assessment in the oil and gas sector." J. Constr. Eng. Manage., 142(10), 04016052.

Sawacha, E., Naoum, S., and Fong, D. (1999). "Factors affecting safety performance on construction sites." Int. J. Proj. Manag., 17(5), 309-315.

Shapira, A., and Simcha, M. (2009). AHP-based weighting of factors affecting safety on construction sites with tower cranes. J. Constr. Eng. Manage., 135(4), 307-318. 
Shea, T., De Cieri, H., Donohue, R., Cooper, B., and Sheehan, C. (2016). "Leading indicators of occupational health and safety: An employee and workplace level validation study." Saf. Sci., 85, 293-304.

Sheehan, C., Donohue, R., Shea, T., Cooper, B., and De Cieri, H. (2016). "Leading and lagging indicators of occupational health and safety: The moderating role of safety leadership." Accident Anal. Prev., 92, 130-138.

Shen, X. and Marks, E. (2015). "Near-miss information visualization tool in BIM for construction safety." J. Constr. Eng. Manage., 10.1061/(ASCE)CO.1943-7862.0001100, 04015100.

SmartMarket Rep. (2013). "Lean construction: Leveraging collaboration and advanced practices to increase project efficiency.” McGraw-Hill Construction, Bedford, MA.

SmartMarket Rep. (2016). "Building a safety culture: Improving safety and health management in the construction industry." McGraw-Hill Construction, Bedford, MA.

Smith, D. (2007). "An introduction to building information modeling." Journal of Building Information Modeling, 12-14. 〈http://www.wbdg.org/pdfs/jbim fall07.pdf〉 (November 19, 2016).

Spear, L.E. (2013). "Improving contractor safety performance." Safety made, 4(3), 22-24.

Suhr, J. (1999). "The Choosing By Advantages decisionmaking system.” Quorum, Westport, CT

Sulankivi, K., Makela, T., and Kiviniemi, M. (2009). "BIM-based site layout and safety planning." In Proc., 1st International Conference on Improving Construction and Use through Integrated Design Solutions, CIB IDS, Finland.

Szymberski, R. (1997). “Construction project safety planning.” Tappi Journal, 80(11), 69-74.

Tam, C., Zeng, S., and Deng, Z. (2004). "Identifying elements of poor construction safety management in China." Saf. Sci., 42(7), 569-586.

Teo, E., and Feng, Y. (2009). "The role of safety climate in predicting safety culture on construction sites." Architect Sci. Rev., 52(1), 5-16.

Teo, P., and Love, P. (2017). "Re-examining the association between quality and safety performance in construction: From heterogeneous to homogeneous datasets." J. Constr. Eng. Manage., 10.1061/(ASCE)CO.1943-7862.0001285, 04017011.

Toellner, J. (2001). "Improving safety and health performance: Identifying and measuring leading indicators." Prof. Saf., 46(9), 42-47.

Toole, T. M. (2002). "Construction site safety roles." J. Constr. Eng. Manage., 10.1061/(ASCE)0733-9364(2002)128:3(203), 203-210.

Toole, T. M., and Gambatese, J. (2008). "The trajectories of prevention through design in construction.” J. Safety Res., 39(2), 225-230.

Toole, T. M., Gambatese, J., and Abowitz, D. (2016). "Owners' role in facilitating prevention through design.” J. Prof. Issues Eng. Educ. Pract., 10.1061/(ASCE)EI.1943-5541.0000295, 04016012.

Torraco, R. J. (2005). "Writing integrative literature reviews: Guidelines and examples." Human resource development review, 4(3), 356-367.

Tymvios, N. and Gambatese, J. (2016). "Direction for generating interest for design for construction worker safety_A Delphi study.” J. Constr. Eng. Manage., 10.1061/(ASCE)CO.1943-7862.0001134, 04016024.

Vecchio-Sadus, A., and Griffiths, S. (2004). "Marketing strategies for enhancing safety culture." Saf. Sci., 42(7), 601-619. 
Wachter, J. (2012). “Trailing safety indicators: Enhancing their value through statistics.” Prof. Saf., 57 (4), 48-60.

Wanberg, J., Harper, C., Hallowell, M., and Rajendran, S. (2013). "Relationship between construction safety and quality performance.” J. Constr. Eng. Manage., 10.1061/(ASCE)CO.1943-7862.0000732, 04013003.

Whitman, J. (2014). “Construction site utilization planning best practices.” Doctoral dissertation, Auburn University, Auburn, AL.

Zahoor, H., Chan, A., Utama, W., Gao, R., and Zafar, I. (2017). "Modeling the relationship between safety climate and safety performance in a developing construction industry: a cross-cultural validation study.” Int. J. Environ. Res. Publ. Health, 14(4), 351-369.

Zhang, S., Teizer, J., Lee, J., Eastman, C., and Venugopal, M. (2013). "Building information modeling (BIM) and safety: Automatic safety checking of construction models and schedules." Automation in construction, 29, 183-195. 